\title{
Early retirement across Europe: Does non-standard employment increase participation of older workers?
}

Jim Been and Olaf van Vliet

Leiden University

Jim Been and Olaf van Vliet (Leiden University) analyze the variation in early retirement across 13 European countries. The results of this study show that for men, part-time employment reduces early labor market withdrawal.

Although the participation rates of older workers have been rising for both men and women in many European countries, the participation rates are still low compared to those of primeage workers. One prominent explanation for the low participation rates of older people is that once older people are unemployed or receive disability benefits, relatively few of them start working again before they reach the statutory retirement age. As a result, such social insurance programs function in practice quite often as an arrangement to smoothen the transition from work to retirement.

Another class of factors is the rise of non-standard forms of employment. Older people may opt for part-time work and self-employment because it provides flexibility in working hours such that these types of employment may be used as gradual retirement mechanism. Whether non-standard forms of employment can explain the cross-national variation in labor market participation of older workers has not been analyzed thus far. In this study, we analyze the variation in early labor market withdrawal across 13 European countries over the period $1995-2008$.

Our empirical analysis finds that for men, part-time employment reduces early labor market withdrawal. The results suggest that this is mainly because of the possibility to reduce working hours as we find that specifically voluntary part-time employment induces labor force participation at older ages. This relationship is less strong for women. With regard to 
self-employment, our results provide no evidence for substitution effects between selfemployment among older workers and early retirement. Furthermore, we find that unemployment among older workers contributes to early labor market withdrawal.

The policy implication of our findings would be that facilitating part-time work contributes to higher labor market participation among older workers. However, facilitating part-time work could also induce a reduction in working hours among persons who would otherwise have worked full-time. Interestingly, our analysis suggests that increases in part-time employment did not reduce working hours. Instead, the results even suggest positive effects.

\section{Reference}

Jim Been and Olaf van Vliet (2014) Early retirement across Europe: Does non-standard employment increase participation of older workers? Netspar Discussion Paper 10/2014044. 